8. O'Connell TF, Ham SA, Hart TG, Curlin FA, Yoon JD. A national longitudinal survey of medical students' intentions to practice among the underserved. Acad Med. 2018;93(1):90-97.

9. Jeffrey J, Dumont RA, Kim GY, Kuo T. Effects of international health electives on medical student learning and career choice: results of a systematic literature review. Fam Med. 2011;43(1):21-28.

10. NACHC. Access Transformed: Building a Primary Care Workforce for the 21st Century. Washington, DC: Robert Graham Center; 2008.

$\because$ NAPCRG rom nureac

Ann Fam Med 2020;18:189-190. https://doi.org/10.1370/afm.2524.

\section{THE DECLARATION OF ASTANA AND WHAT IT MEANS FOR THE GLOBAL ROLE OF NAPCRG AND WONCA}

In Astana on October 27, 2018, the Global Conference on Primary Health Care organized by the World Health Organization (WHO) and UNICEF welcomed a declaration to strengthen primary health care in pursuit of health and well-being, and pursue universal health coverage-access for all to high-quality health care, without undue financial burden. ${ }^{1}$ This paper, based on the International Forum of the 2019 NAPCRG conference, explores the critical roles of multinational primary care organizations such as NAPCRG and the World Organization of Family Doctors (WONCA) in realizing the vision of "Astana".

The Astana Declaration acknowledged the Alma Ata Declaration of $1978^{2,3}$ commitment to the fundamental role of strong primary health care for population health. At the same time it embraced the United Nations (UN) Sustainable Development Goals, ${ }^{4}$ stressed the importance of equity, and advocated the concept for health as being fundamental for societal development.

The Declaration ${ }^{1}$ presents 3 interconnected components: empowered populations and communities that can prioritize and co-design responses to their health needs, high-quality primary care, integrated with public health ind multi-sectoral policy and action. Integrated health systems with primary care as a core function are required for its implementation, which must be linked to community services. It is the totality of this integration that is primary health care. In Astana, "primary care" and "primary health care" were used interchangeably, but it is important to understand that primary care is a core function of primary health care, and as such a priority. To implement, there is a need to build primary care research capacity globally.
A strong point of the Astana compared to earlier Declarations on primary health care is in its connection to the UN Sustainable Development Goals. ${ }^{4}$ This connects the Astana Declaration, strengthened by the High-Level Meeting on universal health coverage ${ }^{5}$ to the heads of state, and not just ministries of health. Pursuing health as a condition for societal development will enlarge partnerships and stakeholders for collaboration in health reforms.

Although the Declaration builds on high-quality primary care, a major shortcoming is its failure to acknowledge the professionalism of this field, and the professionals with their expertise to provide its value. This ignored an earlier WHO resolution that had stressed the importance of primary care nurses, midwives, allied health professionals, and family physicians, with the need of professional training and retention in their positions in communities around the world. ${ }^{6}$

This stresses the importance of continued advocacy for high-quality primary care and the disciplines and competencies required of its teams to deliver it. A central lesson from Astana is that declarations and resolutions are only able to guide policy when their content is consistently shared between all stakeholders. Here is a particular responsibility for WONCA and NAPCRG with their status in the international domain of primary care: primary care is essential for realizing universal health coverage, therefore every community around the world needs access to multidisciplinary primary care teams.

Teaching, training, and research are essential in realizing this ambition, and primary care should be an integral part of the education of future nurses, midwives, allied health professionals, and physicians. To ensure this, primary care must be part of every medical school and training institute of health professionals globally. Training programs should be multidisciplinary, in order to support robust primary care teams in every community of the world.

The performance of primary care teams has to be supported by research: building a robust primary care research capacity and infrastructure for the generation of new knowledge and the implementation of evidence and policy is a high priority-in particular in low- and middle-income countries.

NAPCRG and WONCA, as leading international organizations in primary care, see it as their responsibility to support WHO and UN to realize the ambitions of the Astana declaration, and will intensify their mutual collaboration in this to secure access to primary care teams with family physicians in every community of the world. ${ }^{7}$ All nations need to prioritize:

- A department of primary care in every medical school $^{7}$ 
- High-quality community-based training of all nurses, midwifes, allied health professionals and family doctors

- The building of primary care research capacity with active involvement of primary care practices and practice teams

Given the multidisciplinary nature of primary care, NAPCRG and WONCA reach out to other international organizations that look after the professional and academic quality of nurses, midwifes, allied health professionals, and family doctors.

This summary is the result of the International Forum "Health Systems After 'Astana': The Evolving International Role of Primary Health Care and Family Medicine,"' November 17, 2019, 47th NAPCRG Conference, Toronto, Canada.

Corresponding author Prof Chris van Weel, Radboud Institute of Health Sciences, Department of Primary and Community Care, Radboud University Nijmegen, The Netherlands, and Australian National University, Canberra, Australia. Chris. vanWeel@radboudumc.nl,DrTim olde Hartman, MD,PbD, Radboud Institute of Health Sciences, Department of Primary and Community Care, Radboud University Nijmegen, The Netherlands, Dr Katherine Rouleau, MDCM, CCFP, MHSc. St-Michael's Hospital. Department of Family and Community medicine, University of Toronto, Canada, Prof Andrew Bazemore, MD MPH, SVP for Research \& Policy, American Board of Family Medicine ${ }_{i}$ Co-Director, Center for Professionalism \& Value in Healthcare, Prof Jack Westfall, MD, MPH. Robert Grabam Center Policy Studies in Family Medicine \& Primary Care, Washington DC, USA, Prof Grant Russell, MBBS PbD. Department of General Practice, School of Primary \& Allied Health Care, Monash University, Melbourne Victoria, Austra- lia, Prof Michael Kidd, MBBS MD, Department of Family and Community Medicine, University of Toronto, Canada, Prof Amanda Howe, MD, Norwich Medical School, Faculty of Medicine and Health Sciences, University of East Anglia, Norwich, UK, Prof Robert L. Pbillips, Jr., MD MSPH, Center for Professionalism and Value in Health Care, American Board of Family Medicine Foundation, Washington DC, USA, Dr Donald Li, MBBS. President of WONCA. Department of Family Medicine, Hong Kong Academy of Medicine, Hong Kong, Prof Felicity Goodyear-Smith, MBCbB, MD, Department of General Practice \& Primary Health Care, University of Auckland, Auckland, New Zealand.

\section{References}

1. World Health Organization. Astana Declaration: From Alma-Ata Towards Universal Health Coverage and the Sustainable Development Goals. Astana, Kazakhstan: Global Conference on Primary Health Care; 2018.

2. World Health Organization. Alma-Ata Declaration on Primary Healthcare: Report of the International Conference on Primary Health Care. Geneva, Switzerland: World Health Organization; 1978.

3. World Health Organization. The World Health Report 2008: Primary Health Care - Now More Than Ever. Geneva, Switzerland: World Health Organization; 2008.

4. United Nations. Sustainable Development Goals. Geneva, Switzerland: United Nations; 2015.

5. General Assembly of the United Nations. 2019 UN High-Level Meeting on Universal Health Coverage (UHC). New York, NY: United Nations; 2019. https://www.un.org/pga/73/event/universal-healthcoverage/. Accessed Sep 23, 2019.

6. Sixty-second World Health Assembly. Primary Health Care, Including Health System Strengthening. WHA6212. Geneva, Switzerland: World Health Organization; 2009:3.

7. World Organization of Family Doctors. Wonca World Conference 2007 in Singapore - the Singapore Statement, Resolutions 2007. Singapore: World Organization of Family Doctors; 2007 